\title{
microRNA-194 suppresses osteosarcoma cell proliferation and metastasis in vitro and in vivo by targeting CDH2 and IGF1R
}

\author{
KANG HAN $^{1,2^{*}}$, TINGBAO ZHAO ${ }^{2 *}$, XIANG CHEN $^{3}$, NA BIAN $^{1}$, TONGTAO YANG $^{1}$, \\ QIONG MA ${ }^{1}$, CHENGKUI CAI $^{1}$, QINGYU FAN ${ }^{1}$, YONG ZHOU $^{1}$ and BAOAN MA ${ }^{1}$
}

\author{
${ }^{1}$ Department of Orthopedic Surgery, Orthopedics Oncology Institute of Chinese PLA, Tangdu Hospital, \\ Fourth Military Medical University, Xi'an, Shaanxi; ${ }^{2}$ Department of Spinal Cord Injury, General Hospital of Jinan Military \\ Area Command of Chinese PLA, Jinan, Shandong, P.R. China; ${ }^{3}$ Department of Baylor College of Medicine, Houston, TX, USA
}

Received June 18, 2014; Accepted July 25, 2014

DOI: 10.3892/ijo.2014.2571

\begin{abstract}
Studies have shown that miR-194 functions as a tumor suppressor and is associated with tumor growth and metastasis. We studied the effects of miR-194 in osteosarcoma and the possible mechanism by which miR-194 affected the survival, apoptosis and metastasis of osteosarcoma. Both human osteosarcoma cell lines SOSP-9607 and U2-OS were transfected with recombinant lentiviruses to regulate miR-194 expression. Overexpression of miR-194 partially inhibited the proliferation, migration, and invasion of osteosarcoma cells in vitro, as well as tumor growth and pulmonary metastasis of osteosarcoma cells in vivo. Potential miR-194 target genes were predicted using bioinformatics. Luciferase reporter assay, real-time quantitative PCR and western blotting confirmed that $\mathrm{CDH} 2$ (N-cadherin) and IGFIR were targets of miR-194. Using real-time quantitative PCR, we evaluated the expression of miR-194 and two miR-194 target genes, CDH2 and IGFIR in osteosarcoma samples from 107 patients and 99 formalin- or paraformalin-fixed paraffin-embedded tissues. The expressions of the target genes were also examined in osteosarcoma samples using immunohistochemistry. Overexpression of miR-194 inhibited tumor growth and metastasis of osteosarcoma probably by downregulating $C D H 2$ and IGFIR. miR-194 may prove to be a promising therapeutic agent for osteosarcoma.
\end{abstract}

Correspondence to: Professor Baoan Ma or Professor Yong Zhou, Department of Orthopedic Surgery, Orthopedics Oncology Institute of Chinese PLA, Tangdu Hospital, Fourth Military Medical University, Xi'an, Shaanxi, P.R. China

E-mail: gan_7758525@163.com

E-mail: gan_7758525@sina.com

*Contributed equally

Key words: osteosarcoma, miR-194, CDH2, IGF1R, metastasis, proliferation

\section{Introduction}

Osteosarcoma (OS) is the most common primary malignant neoplasm in adolescents with an annual estimated worldwide incidence of 4 million, with a peak incidence at the age of 15-19 years (1). Osteosarcoma is associated with abnormal differentiation caused by genetic and epigenetic changes. Advances in osteosarcoma therapy have enhanced patient outcomes. The most effective regimens currently include neoadjuvant and adjuvant chemotherapy coupled with local control that usually consists of limb-sparing surgery (2). Unfortunately, the cure rate is still very poor due to pulmonary metastases (3). Therefore, the identification of effector molecules and signaling pathways underlying resistance to chemotherapy and malignancy is vital for osteosarcoma treatment. Studies have investigated the genes associated with metastasis of osteosarcoma, and microRNAs (miRNAs) have become a new research hotspot in gene therapy.

microRNAs (miRNAs) are a class of 22-25 nucleotide RNA molecules that negatively regulate gene expression in animals and plants $(4,5)$. Since the discovery of the role of miRNAs in Caenorhabditis elegans development (6), a frequent disregulation of miRNAs has been observed in diverse cancers, including synovial sarcoma, colon cancer (7), breast cancer (8), glioma (9), glioblastoma (10), hepatocellular carcinoma (11), lung (12) and gastric cancer (13). Some of these miRNA expression profiles showed downregulation in tumors compared with normal tissue (14), like miR-127 in human bladder cancers (15) and microRNA-34a in OS (16). However, other miRNAs are upregulated in tumors, such as miR-150 in gastric cancer (17) and miR-17-92 cluster in renal cell carcinoma (18). The alterations in miRNA expression may play a crucial role in the initiation and progression of the above cancers (19), functioning as a novel class of oncogenes and tumor suppressors $(20,21)$. Thus, miRNAs play an essential role in basic physiologic processes, such as development, differentiation, proliferation and apoptosis (22). However, their biological function remains largely unknown.

miR-194 is specifically expressed in the human gastrointestinal tract and is induced during intestinal epithelial cell differentiation (23). The regulatory role of miR-194 was first studied in normal and malignant cells of the gastrointestinal 
tract (24). Overexpression of miR-194 in gastrointestinal cancer cells suppresses cell migration, invasion and metastasis (24). miR-194 functions as a tumor suppressor gene by downregulating targets such as $\mathrm{SSH} 2, \mathrm{HBEGF}, \mathrm{IGF} 1 \mathrm{R}, \mathrm{CDH} 2$ (N-cadherin) and TLN2 (23-27). Hepatocyte nuclear factor (HNF) also induces miR-194 expression during intestinal epithelial cell differentiation (23). In colon cancer tissue, miR-194 was downregulated relative to normal mucosa (28). Low expression of miR-194 has been associated with large tumor size and advanced stage in gastric cancer (29). In endometrial cancer cells, miR-194 has been reported to inhibit self-renewal factor BMI-1, reduce cell invasion and inhibit epithelial-mesenchymal transition (EMT) (30). The mutations of p53 tumor suppressor gene, which directly regulates the expression of miR-194, were found in $20-60 \%$ of sporadic OS (31). The reports suggested that miR-194 may function as a tumor suppressor in OS. However, the effects of miR-194 in osteosarcoma have not been completely elucidated. Therefore, it is of great significance to further study the function and mechanism of miR-194 in osteosarcoma.

We carried out in vitro and in vivo experiments to evaluate the effects of miR-194 and its possible direct targets, IGF1R and $C D H 2$, in tumor growth and metastasis of SOSP-9607 and U2-OS cells. We also predicted its putative target genes, which are correlated with tumor growth and metastasis, using bioinformatics analysis. We report for the first time that overexpression of miR-194 inhibited growth and metastasis of osteosarcoma. In addition, miR-194 specifically downregulated the expression of IGFIR and CDH2. miR-194 gene therapy may prove to be a promising therapy for tumorsuppression in osteosarcoma.

\section{Materials and methods}

Ethics statement. All research involving human tissue samples and animals was approved by the Ethics Review Committee of Fourth Military Medical University, Xi'an, Shaanxi, China (approval ID:2013106) and written informed consent was obtained from all participating patients.

Human tissue samples. A total of 107 pairs of human osteosarcoma tissue samples were obtained from patients who underwent surgical resection at the Tangdu Hospital of Fourth Military Medical University between 2007 and 2010 and were diagnosed with osteosarcoma based on histopathological evaluation. The biopsies were immediately snap-frozen in liquid nitrogen after resection and stored at $-80^{\circ} \mathrm{C}$. One section of each sample was stained with hematoxylin-eosin (H\&E) for histopathological evaluation. The clinical stage of these osteosarcoma patients was classified according to the sixth edition of the tumor-node-metastases (TNM) classification of the International Union Against Cancer (UICC).

All 107 osteosarcoma patients were studied in a follow-up. The median follow-up was 42 months (range, 5-68 months). During the follow-up period, 62 patients $(57.9 \%)$ died of disease. Distant metastases developed in 52 patients at a mean of 12.7 months (range, 3-41 months) after the original diagnosis. Of these patients, 13 had bone metastases and 43 had lung metastases (4 patients had both bone and lung metastases).
Cell culture. Human osteosarcoma cell lines SOSP-9607 were established and reserved in our laboratory as previously described (32). Human osteosarcoma cell lines U2-OS were purchased from the American Type Culture Collection (ATCC, Manassas, VA, USA) and used within 6 months of the purchase. SOSP-9607 cells were maintained in RPMI-1640 medium (HyClone, Logan, UT, USA) supplemented with $10 \%$ fetal bovine serum (FBS; HyClone), $2.0 \mathrm{mM}$ L-glutamine, $100 \mathrm{U} / \mathrm{ml}$ penicillin and $100 \mu \mathrm{g} / \mathrm{ml}$ streptomycin, and incubated at $37^{\circ} \mathrm{C}$ in a humidified incubator supplemented with $5 \%$ $\mathrm{CO}_{2}$ and $95 \%$ air. U2-OS cells were maintained in the same conditions, except DMEM medium was used. Cell line authentication was performed by the Orthopedics Oncology Institute of Chinese PLA according to the UKCCCR guidelines every 2-3 months, including mycoplasma test by PCR and measurement of cell proliferation by counting.

Generation of stable cell lines. Recombinant lentiviruses containing overexpression of miRNA-194, for knocking down miRNA-194 and miRNA control were purchased from Shanghai Genechem Co., Ltd. (Shanghai, China). The precusor sequence of miR-194 was used for overexpression as follows: AUGGUGUUAUCAAGUGUAACAGCAACUCCAUGUGG ACUGUGUACCAAUUUCCAGUGGAGAUGCUGUUACU UUUGAUGGUUACCAA. The reverse complementary sequence of miR-194 was used for the knock-down as follows: TC CACATGGAGTTGCTGTTACA. Besides the multiple clone sites of lentivirus expression vectors, there also was a GFP reporter driven by an independent promoter (SV40 promoter) to indicate the infection rate of the virus timely.

To generate the stable cell line, $1 \times 10^{4}$ cells were transfected with $5 \times 10^{5}$ transducing units of lentiviruses. The supernatant was removed after $24 \mathrm{~h}$ and replaced with complete culture medium. Infection efficiency was confirmed by RT-PCR $96 \mathrm{~h}$ after infection and the cells were selected with $1 \mu \mathrm{g} / \mathrm{ml}$ puromycin for 2 weeks.

Reverse transcription and quantitative real-time PCR. Total RNA containing miRNA and mRNA was extracted from cells with TRIzol ${ }^{\circledR}$ reagent (Invitrogen, Carlsbad, CA, USA), or from formalin- or paraformalin-fixed, paraffin-embedded (FFPE) tissues with RecoverAll ${ }^{\mathrm{TM}}$ Total Nucleic Acid Isolation kit (Ambion, Foster City, CA, USA; cat no. AM1975), according to the manufacturer's instructions. The RNA was quantified by absorbance at $260 \mathrm{~nm}$ and transcribed into cDNA using BioRT Two-Step RT-PCR kit (Bioer Technology, Inc., Hangzhou, China). To evaluate IGF-1R and N-cadherin expression levels, $1 \mu \mathrm{g}$ of total RNA was used for reverse transcription with iScript cDNA Synthesis kit (Bio-Rad Laboratories, Hercules, CA, USA), according to the manufacturer's instructions. The sequences of the forward and reverse primers for IGF1R were 5'-CGACATTGAGGAGGTCAC AGA-3' and 5'-TGGGCACGAAGATGGAGTT-3'. The sequences of the forward and reverse primers for $\mathrm{N}$-cadherin were 5'-GTCAGCAGAAGTTGAAGAAATAGTG-3' and 5'-GCAAGTTGATTGGAGGGATG-3'.

The sequences of the forward and reverse primers for glyceraldehyde-3-phosphate dehydrogenase (GAPDH) were 5'-TGGGTGTGAACCATGAGAAGT-3' and 5'-TGAGTCC TTCCACGATACCAA-3'. The expression level of GAPDH 
was used as a control. To evaluate hsa-miR-194 levels, the sequences of primers for miR-194: 5'-ACACTCCAGCTGGG TGTAACAGCAACTCCAT-3' were used. U6 was used as a control.

Apoptosis, proliferation and cell cycle assays. Cultured cells were grown in 6-, 24- and 96-well plates. Apoptosis and cell cycle were measured using flow cytometry. The procedures were performed as previously described (33). Cell viability was examined using the 3-(4,5-dimethylthiazol-2-yl)-2,5-diphenyltetrazolium bromide (MTT) assay. MTT was performed at $24,48,72,96,120$ and $144 \mathrm{~h}$. The absorbance at $492 \mathrm{~nm}$ was measured after incubation with $20 \mu \mathrm{l}$ of MTT for $4 \mathrm{~h}$. The curve of cell proliferation was then drawn and the proliferation efficiency was examined. There were 6-wells in each group, the experiments were repeated three times independently and the results were given as means $\pm \mathrm{SD}$. The plate clone formation assay was performed as previously described (34). Clones with $>50$ cells were counted with an ordinary optical microscope and the clone formation rate was calculated with the following formula: Plate clone formation efficiency $=$ (number of clones/ number of cells inoculated) $\mathrm{x} 100 \%$.

Transwell cell migration and Matrigel invasion assays. The invasive potential of cells was measured in $6.5 \mathrm{~mm}$ Transwell with 8.0-mm pore polycarbonate membrane insert (cat. 3422; Corning, NY), according to the manufacturer's instructions. The filter of the top chamber was coated with $50 \mu \mathrm{l}$ of diluted Matrigel and incubated at $37^{\circ} \mathrm{C}$ for $2 \mathrm{~h}$. The lower chambers were filled with $600 \mu \mathrm{l}$ of RPMI-1640 medium containing 5\% fetal bovine serum (FBS) as chemoattractant. The suspension of 5,000 cells in $100 \mu \mathrm{l}$ migration medium was added into each top chamber. After the cells were incubated for $16 \mathrm{~h}$, the noninvading cells that remained on the upper surface were removed with a cotton swab. The invasive cells in the lower surface of the membrane insert were fixed with $4 \%$ paraformaldehyde for $30 \mathrm{~min}$, permeabilized with $0.2 \%$ Triton $\mathrm{X}-100$ at room temperature for $15 \mathrm{~min}$ and then stained with $0.1 \%$ crystal violet for $5 \mathrm{~min}$. The number of cells in the lower surface, which had invaded through the membrane, was counted under a light microscope in five random fields at a magnification of $\mathrm{x} 100$. The experiments were repeated three times independently and results were expressed as means \pm SD.

The procedure for Transwell migration assays was the same as the Transwell invasion assay except that the filter of top chamber was not coated with Matrigel.

Wound healing migration assay. When the transfected and untransfected SOSP-9607 and U2-OS cells were grown to confluence, a scratch in the cell monolayer was made using a micropipette tip. Following incubation of the cells under standard conditions for $24 \mathrm{~h}$, the plates were washed twice with fresh medium and images were captured at different times. The migration potential was estimated by counting the cells that migrated from the wound edge. The cell migration rate was obtained by counting three fields per area and represented as the average of six independent experiments over multiple days.

Animal studies. Four-week-old female nude mice (BALB/c, nu/nu; Experimental Animal Centre of the Fourth Military
Medical University in China), 17-22 g in weight, were maintained under specific pathogen-free conditions with 12-h light/12-h dark cycles at $26-28^{\circ} \mathrm{C}$ and $50-65 \%$ humidity. Animal feed and underpad, which were purchased from the Experimental Animal Center, Fourth Military Medical University, were autoclaved and vacuum packed. The water was adjusted to a $\mathrm{pH}$ value of 2.8 and autoclaved before use.

Animal experiments were performed to evaluate orthotopic tumor growth and spontaneous pulmonary metastasis properties of osteosarcoma cells in vivo. Briefly, 4 groups SOSP-9607 cells (overexpression of miRNA-194, for knocking down miRNA-194, miRNA control and untransfected cells) suspension of 100,000 cells in $100 \mu 1$ were injected into the proximal tibia of each anesthetized nude mouse $(n=10$ animals per group). Every 7 days post-inoculation, the length and width of individual orthotopic tumor were measured with calipers, and the volume $\left(\mathrm{mm}^{3}\right)$ was calculated according to the formula: $1 / 2 \times$ length $\times$ width $^{2}$ (35). The curve of orthotopic tumor growth was depicted 42 days after inoculation mouse lungs and orthotopic tumors were harvested and weighed. miR-194 expression levels in the orthotopic tumors were tested using real-time RT-PCR, and the number of pulmonary metastatic tumor nodules was counted under a low-power dissecting stereomicroscope. Finally, mouse lungs were fixed with $10 \%$ neutral-buffered formalin, embedded in paraffin, sectioned at $6 \mu \mathrm{m}$ and stained with H\&E. The pulmonary metastases were imaged under a light microscope at magnifications of $\mathrm{x} 40$, $\mathrm{x} 100,2 \mathrm{x} 00$ and $\mathrm{x} 400$.

Protein extraction and western blot analysis. Protein extracts were prepared through a modified RIPA buffer with $0.5 \%$ sodium dodecyl sulfate (SDS) in the presence of a proteinase inhibitor cocktail (Complete Mini; Roche Diagnostics, Basel, Switzerland) and then were performed as previously described (36).

Luciferase reporter assay. To validate $I G F 1 R$ and $N$-cadherin as target genes of miR-194 in osteosarcoma cells, luciferase assay was performed as previously described (33).

Target prediction. Bioinformatics analysis was carried out using specific programs: Pictar (http://pictar.mdc-berlin.de/), miRanda (http://www.microrna.org) and TargetScan (http:// www.targetscan.org/).

Immunohistochemistry. The dilution of CDH2 and IGF1R antibody used for immunohistochemistry was 1:100. Immunohistochemistry was carried out as previously described (37). The final scores of CDH2 and IGF1R expression were calculated as previously described (38) and classified as follows: 0-4, low; 5-9, high.

Statistical analysis. All values in the present study were expressed as the means $\pm \mathrm{SD}$, and all error bars represent the standard deviation of the mean. Student's t test, one-way analysis of variance and repeated measures data of ANOVA were used to determine significance. Patient survival and their differences were determined using the log-rank test. Cox regression (proportional hazards model) was used for multivariate analysis of prognostic factors. All statistical tests 

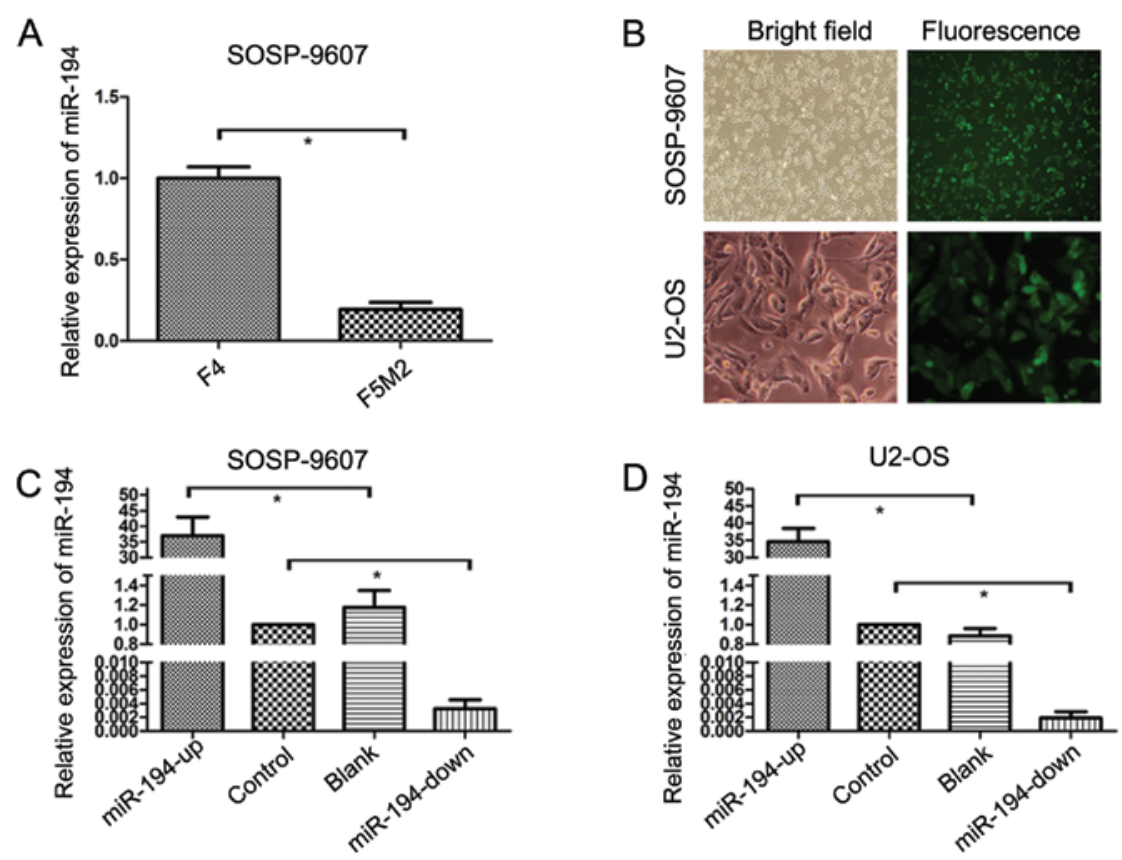

Figure 1. miR-194 expression and miR-194 oligonucleotide transfection in osteosarcoma cells. (A) The qRT-PCR of miR-194 expression in F4 and F5M2 cells ( $\mathrm{P}=0.001)$. (B) SOSP-9607 cells (top) and U2-OS cells (bottom) were observed with white bright (left) and green fluorescence assay (right) in the same view using fluorescence microscopy (magnification, x100, x400). (C) qRT-PCR analysis of miR-194 expression in transfected SOSP-9607 cells. (D) miR-194 expression was assayed in transfected U2-OS cells. U6 was used as an internal loading control. (C and D), data are presented as means \pm SD. Columns, mean of three independent experiments; bars, $\mathrm{SD}$; ${ }^{\mathrm{P}}<0.05$.

were two-sided. $\mathrm{P}<0.05$ was considered statistically significant. Statistical analyses were performed using the SPSS 17.0 software (SPSS, Inc., Chicago, IL, USA).

\section{Results}

Significant difference between F4 and control F5M2 cells. F4 and F5M2 were the sublines originated from SOSP-9607 using limited dilution method $(32,39)$. F5M2 cells show stronger proliferation and invasion than F4 cells, which is useful in studies on metastatic mechanism of osteosarcoma (32). In the present study, we evaluated the expression of miR-194 using quantitative real-time PCR. The results showed that miR-194 expression was significantly lower in F5M2 cells compared with F4 cells (Fig. 1A; $\mathrm{P}<0.001$ ). The results suggested that miR-194 might play a vital role in the metastatic processes.

Generation of stable cell lines. After transfection and selection of cells, the experiments with SOSP-9607 cells and U2-OS cells were divided into four groups including a blank group (untransfected cells), a control group (cells transfected with the control lentivirus), an OE group (overexpression of miRNA-194) and a KD group (knocked down miRNA-194). These GFP-labeled oligonucleotides were detected using fluorescence microscopy (Olympus, Tokyo, Japan) (Fig. 1B).

miR-194 expression levels in four groups were measured using microscopy and stem-loop real-time RT-PCR. The results (Fig. 1C and D) showed that the level of miR-194 was significantly higher in the $\mathrm{OE}$ group and lower in $\mathrm{KD}$ group compared with control and blank groups, respectively. However, there were no significant differences between the control and blank groups. These results indicated that miR-194 recombinant lentiviruses could regulate miR-194 expression effectively in both SOSP-9607 and U2-OS cells. These strategies were then used as the basis of the remaining experiments.

miR-194 inhibits proliferation of osteosarcoma in vitro. The results of MTT assay showed that SOSP-9607 cells in OE groups exhibited a significant decline in proliferation capacity compared with the other three groups $(\mathrm{P}<0.001)$, which were negatively correlated with the exogenous miR-194 level (Fig. 2A). In contrast, cells in the KD group showed significantly enhanced proliferation $(\mathrm{P}<0.001)$. No statistical difference was found between the blank groups and control groups ( $\mathrm{P}=0.541)$. We also tested $\mathrm{U} 2-\mathrm{OS}$ cells (Fig. $2 \mathrm{~A})$. The results were similar to the stably transfected SOSP-9607 cells.

Cell cycle distribution was detected by flow cytometry. The results showed that more cells were in the G0/G1 phase in the OE group compared with the G0/G1 phase in KD group in SOSP-9607 and U2-OS cells (Fig. 2B). These data demonstrated that miR-194 could inhibit the proliferation in both SOSP-9607 and U2-OS cells.

miR-194 induces apoptosis. Apoptosis in the SOSP-9607 cell line was detected using flow cytometry. SOSP-9607 cells in the upregulated groups showed significantly increased spontaneous apoptosis compared with the other three groups $(\mathrm{P}<0.001)$, with the cells in the downregulated groups showing significantly decreased spontaneous apoptosis. The cells in untransfected groups did not produce noticeable changes compared with cells in the control groups ( $\mathrm{P}=0.147)$; (Fig. 3A and C). Similar results were obtained in U2-OS cell lines (Fig. 3B and D). These results showed that miR-194 could induce apoptosis in both SOSP-9607 and U2-OS cells. 

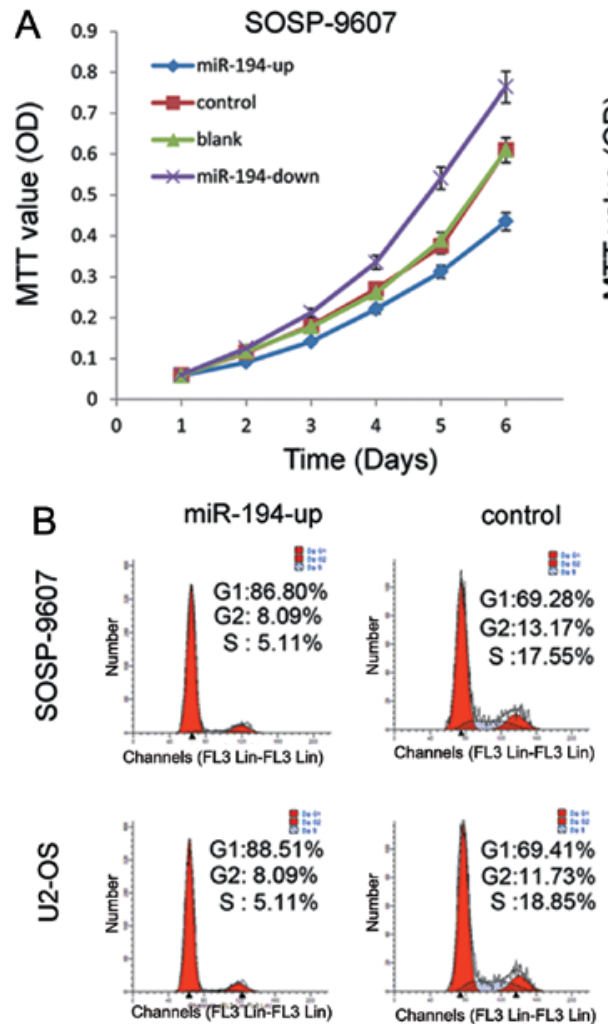

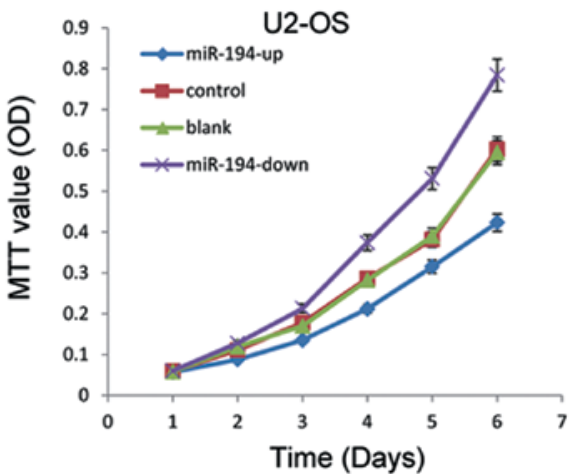

blank miR-194-down
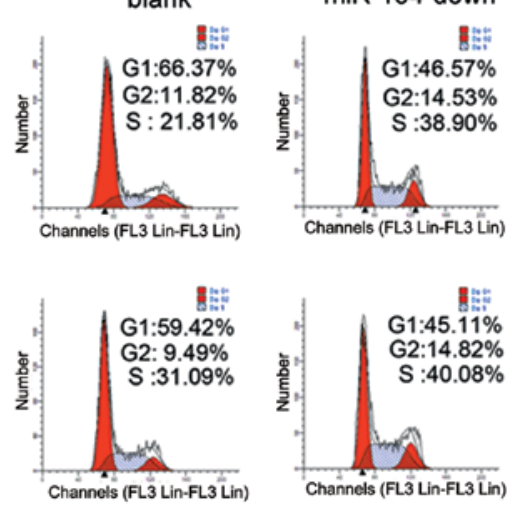

Figure 2. miR-194 inhibits cell proliferation in both SOSP-9607 and U2-OS cell lines. (A) MTT assay of four groups of SOSP-9607 and U2-OS cells. The viable cell number was evaluated as the absorbance at $490 \mathrm{~nm}$ with a reference wavelength of $630 \mathrm{~nm}$. Values of optical density (OD) are expressed as means \pm SD. Point symbol, mean of four independent experiments; bars, SD. (B) Cell cycle distribution of treated SOSP-9607 (top) and U2-OS (bottom) was measured using flow cytometric analysis.
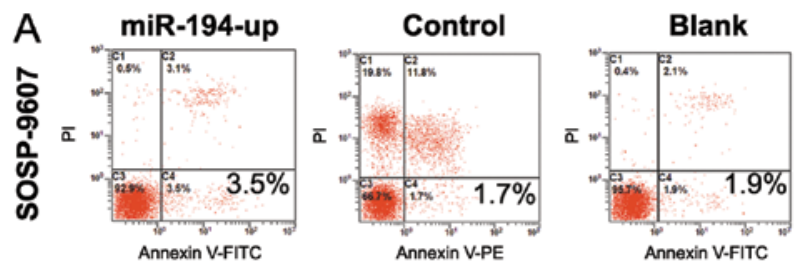

miR-194-down
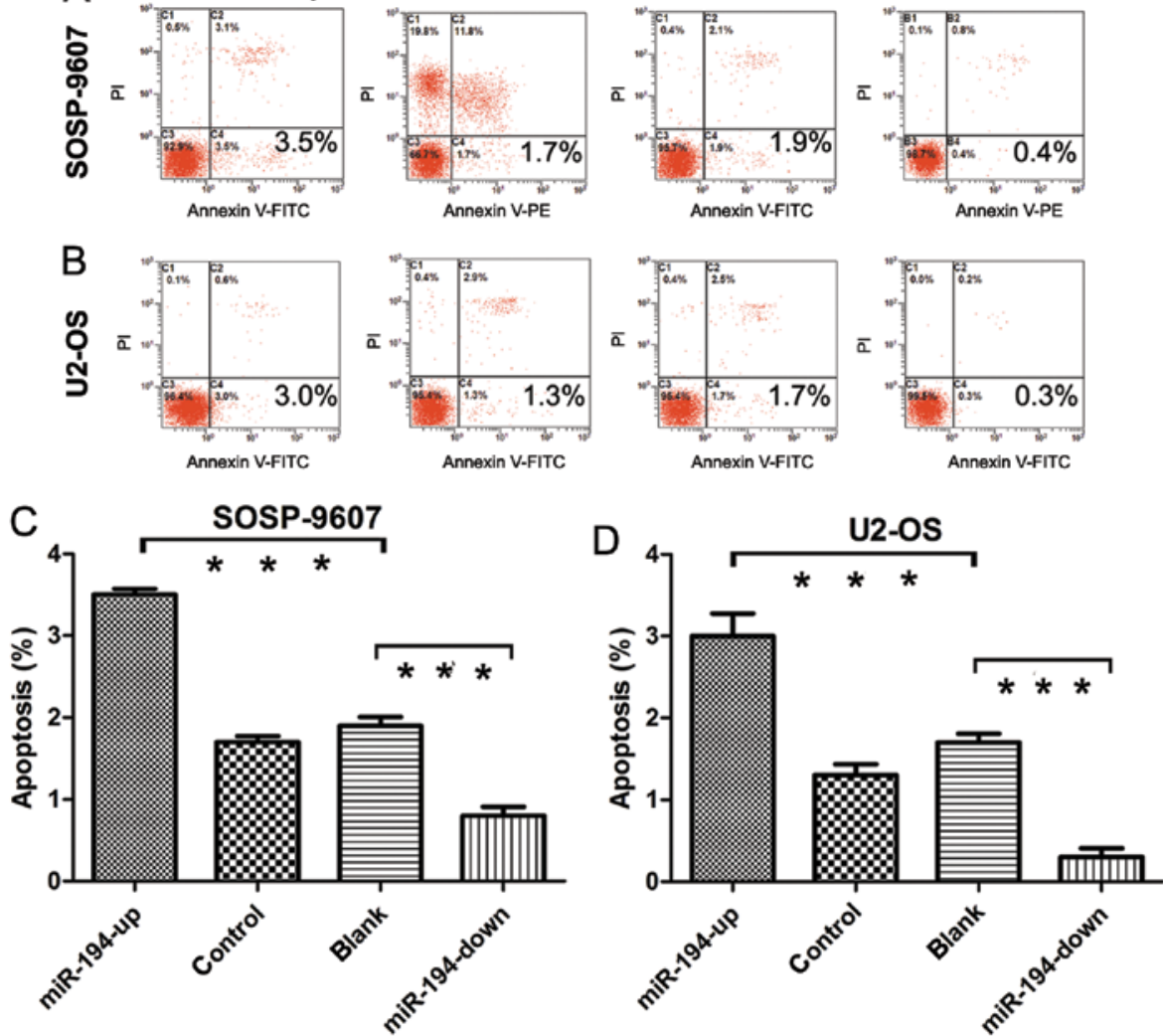

Figure 3. miR-194 induces apoptosis in both SOSP-9607 and U2-OS cells. (A and C) Apoptosis of SOSP-9607 cells were measured using FACS with Annexin V and propidium iodide (PI) staining. (B and D) Apoptosis of U2-OS was measured by FACS with Annexin V and propidium iodide staining. The data are presented as the means $\pm \mathrm{SD}$ in $\mathrm{C}$ and $\mathrm{D}$. Columns, mean of three independent experiments; bars, $\mathrm{SD} ;{ }^{* * *} \mathrm{P}<0.001$. 
A

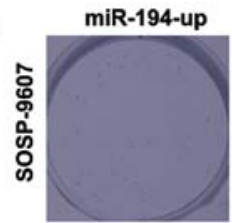

B
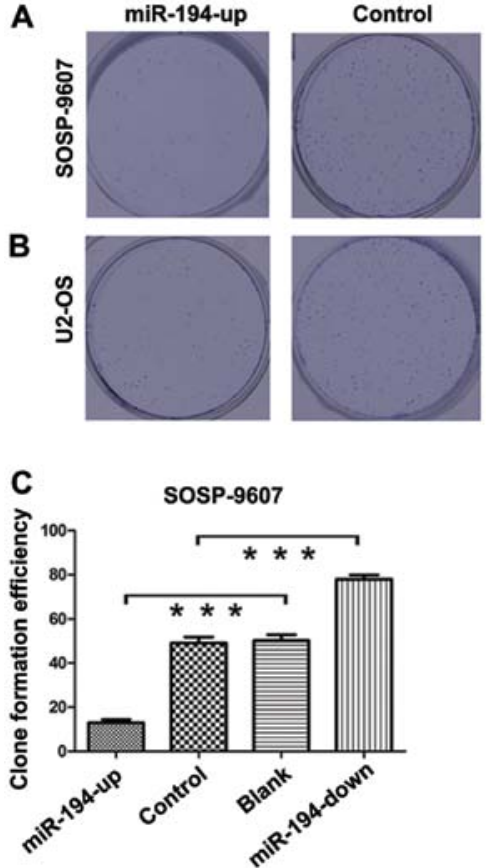

Blank
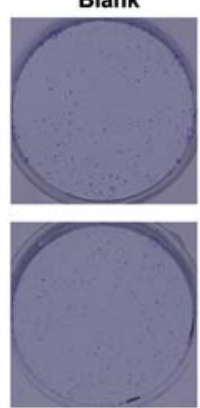

miR-194-down
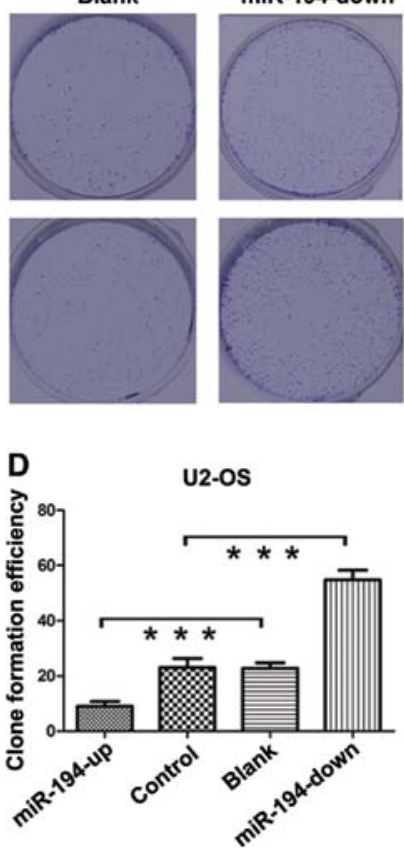

Figure 4. Effect of miR-194 on clonogenicity in both SOSP-9607 and U2-OS cells. (A and C) The clonogenicity of SOSP-9607 cells was captured and counted after 21 days of culture. (B and D) The clonogenicity of U2-OS cells was captured and counted after 21 days of culture; columns, mean of three independent experiments; bars, $\mathrm{SD} ;{ }^{* * * *} \mathrm{P}<0.001$.

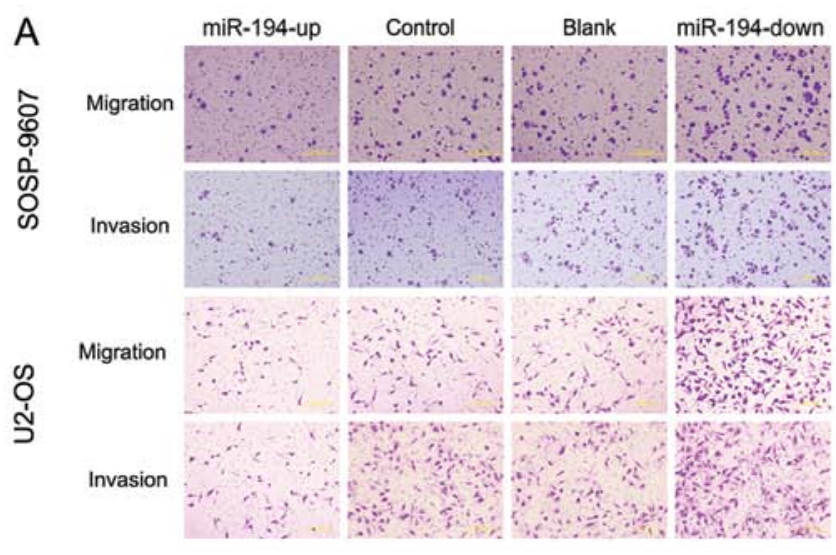

B
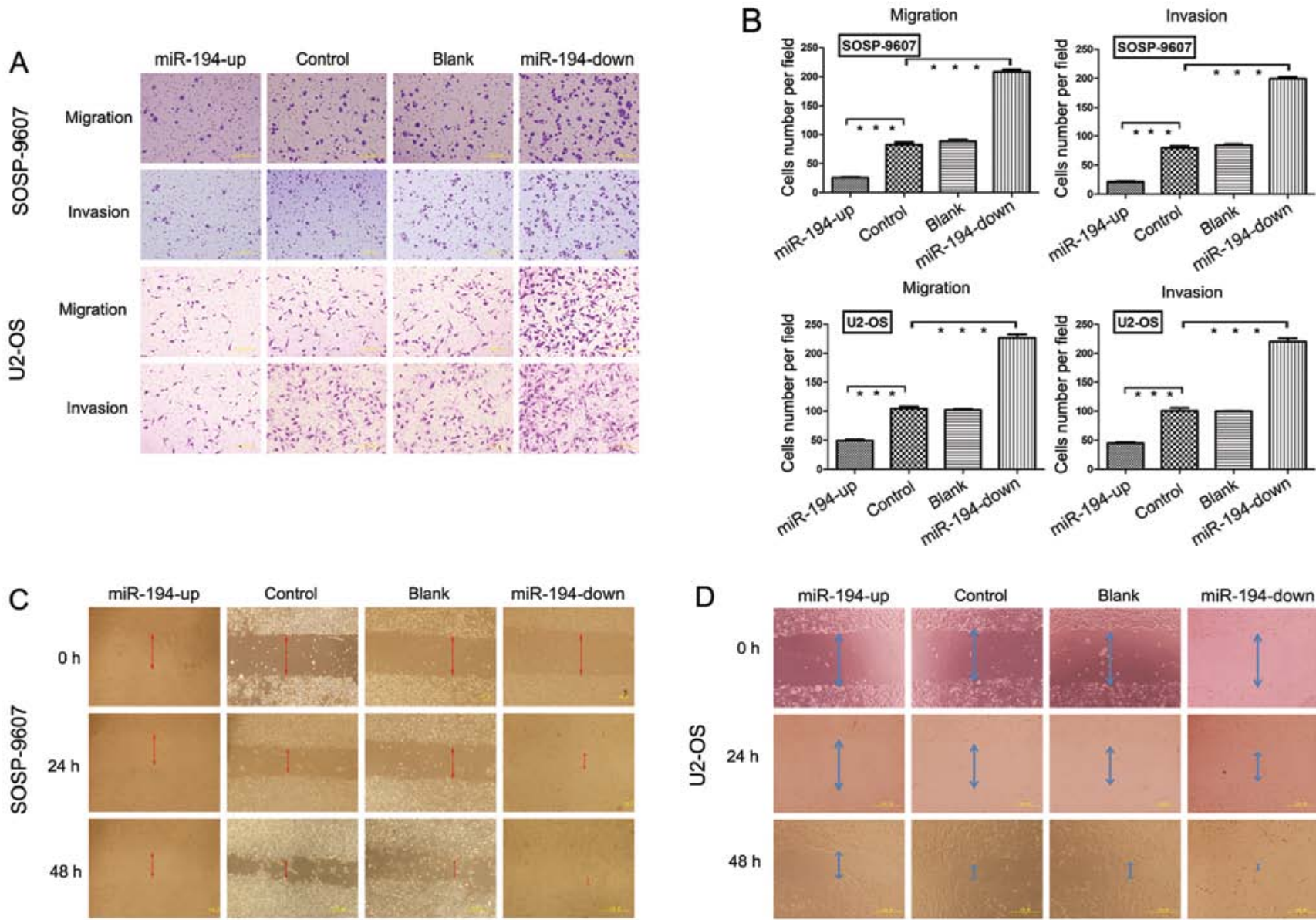

Figure 5. miR-194 inhibits migration and invasion of osteosarcoma in vitro. (A) Representative images of migrated and invaded SOSP-9607 or U2-OS cells on the membrane at a magnification of x200. (B) Quantitative results of the migration and invasion in each group of SOSP-9607 or U2-OS cells are presented, $16 \mathrm{~h}$ after incubation. (C and D) SOSP-9607 or U2-OS cells were seeded in 6-well plates and subjected to wounding on the next day. Images were taken at 0, 24 and $48 \mathrm{~h}$, respectively, after the wound. Data are expressed as means \pm SD; Columns, mean of three independent experiments; bars, $\mathrm{SD} ;{ }^{* * *} \mathrm{P}<0.001$. 

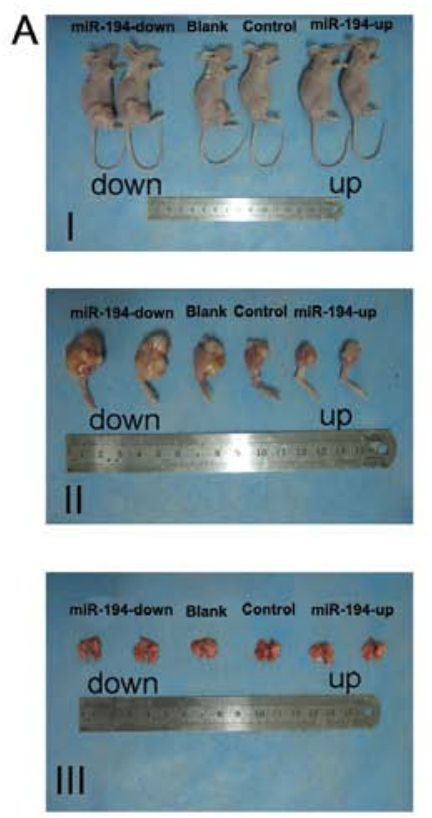
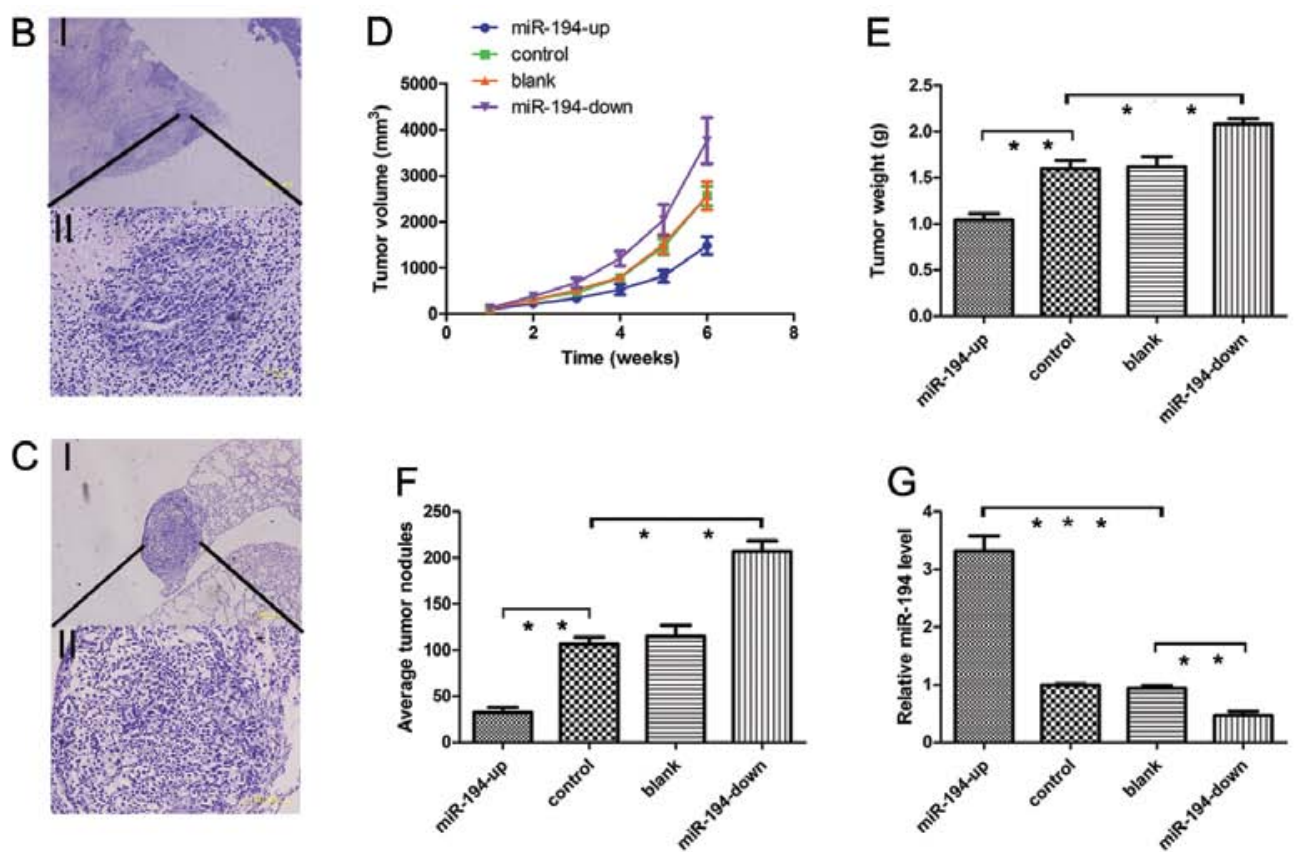

Figure 6. miR-194 inhibits tumor growth and metastasis of osteosarcoma in vivo. (A) I, Representative photographs of tumors on the right legs of mouse; II, Representative imagess of orthotopic tumors harvested 42 days after inoculation. III, Representative images of mouse lungs, 42 days post-inoculation. (B) Representative images of H\&E-stained spontaneous orthotopic tumors at a magnification of x40 (I) and x400 (II). (C) Representative images of H\&E-stained spontaneous lung metastases at a magnification of x100 (I) and x400 (II). (D) Tumor growth curves measured after the inoculation. The length (L) and width (W) of tumor were measured every 7 days after inoculation and the volume of tumor was calculated. (E) Orthotopic tumor weights 42 days post-inoculation. Data are presented as means \pm SD. (F) Graph displaying the total number of tumor nodules per lung in four groups. Data are presented as means \pm SD. (G) Forty-two days after inoculation, miR-194 expression levels were determined in orthotopic tumors. Columns, mean of three independent experiments; bars, $\mathrm{SD} ;{ }^{* *} \mathrm{P}<0.01,{ }^{* * *} \mathrm{P}<0.001$.

Effect of miR-194 onclone formation in SOSP-9607 and U2-OS cells. The clone formation efficiency of SOSP-9607 cells was as follows: OE (12.87 $\pm 2.66 \%)$, control $(49.00 \pm 4.80 \%)$, blank $(50.13 \pm 4.71 \%)$ and KD $(77.93 \pm 3.30 \%)$ groups, respectively, after 21 days of culture (Fig. 4A and C). No significant differences existed between the blank and control SOSP-9607 cells $(\mathrm{P}=0.736)$. The clone formation efficiency of U2-OS cells was: OE $(9.07 \pm 2.93 \%)$, control $(23.00 \pm 5.79 \%)$, blank $(22.8 \pm 3.41 \%)$ and KD (54.87 $\pm 6.07 \%)$ groups, respectively (Fig. 4B and D). No significant difference was observed between the blank and control cells $(\mathrm{P}=0.96)$. Statistical analysis showed that miR-194 inhibits the clonogenicity of osteosarcoma in vitro $(\mathrm{P}<0.001)$.

miR-194 inhibits migration and invasion of osteosarcoma in vitro. Results in the Transwell migration assay showed significantly lower numbers of OE SOSP-9607 cells (25.00 $\pm 2.54 ; \mathrm{P}<0.001)$ compared with blank $(88.00 \pm 6.59)$, control $(83.00 \pm 7.51)$ and KD SOSP-9607 cells $(208.60 \pm 9.04)$ (Fig. 5A and B). No significant difference was seen between the blank and control SOSP-9607 cells $(\mathrm{P}=0.266)$. In the invasion assay, the OE SOSP-9607 cells $(21.00 \pm 2.23 ; \mathrm{P}<0.001)$ passing through the Matrigel were significantly lower than the blank (80.00 \pm 8.30$)$, control $(85.00 \pm 4.12)$ and KD SOSP-9607 cells (199.20 \pm 7.72$)$ (Fig. 5A and B). No significant difference existed between the blank and control SOSP-9607 cells $(\mathrm{P}=0.216)$ (Fig. 5B). Similar results were obtained in U2-OS cell lines (Fig. 5A and B), which strongly indicated that miR-194 had an important role in reducing the migration and invasion of osteosarcoma in vitro.
The wound healing assay showed that cells in OE groups exhibited a significant decrease in migration rate compared to the other three groups. KD groups of SOSP-9607 cells (or U2-OS) nearly closed the wound $48 \mathrm{~h}$ after incubation, but not the other three groups (Fig. 5C and D).

miR-194 inhibits tumor growth and metastasis of osteosarcoma in vivo. Four groups of stable cells (OE, control, blank and KD SOSP-9607) were injected into proximal tibia of young nude mice. To evaluate tumor growth, the length (L) and width (W) of orthotopic tumor were measured every 7 days post-inoculation. The volume of tumor was calculated according to the formula: Volume $=1 / 2 \times \mathrm{L} \mathrm{xW}^{2}$, and the growth curve of orthotopic tumor obtained. Progressive solid tumors were seen in all mice. By contrast, cells in OE groups produced much smaller tumors, while KD group generated the biggest size (Fig. 6A and D; $\mathrm{P}<0.05$ ). The mice were sacrificed 42 days post-inoculation. The mean tumor weight \pm SD of orthotopic tumors were as follows: OE group $1.04 \pm 0.159 \mathrm{~g}$, control group $1.598 \pm 0.198 \mathrm{~g}$, blank group $1.622 \pm 0.240 \mathrm{~g}$ and KD group $2.082 \pm 0.134 \mathrm{~g}$ (Fig. 6A and E). No significant difference was observed between the blank and control cells $(\mathrm{P}=0.842)$. The number of metastatic nodes was dramatically reduced in the nude mice in OE group compared with the other groups (Fig. 6A and F). Tumor and metastases were confirmed based on histopathological evaluation (Fig. 6B and C). Orthotopic tumors in the OE group expressed higher miR-194 levels compared with other groups (Fig. 6G) indicating that exogenous miR-194 significantly inhibited the tumor growth and metastasis in vivo. 


\section{A}
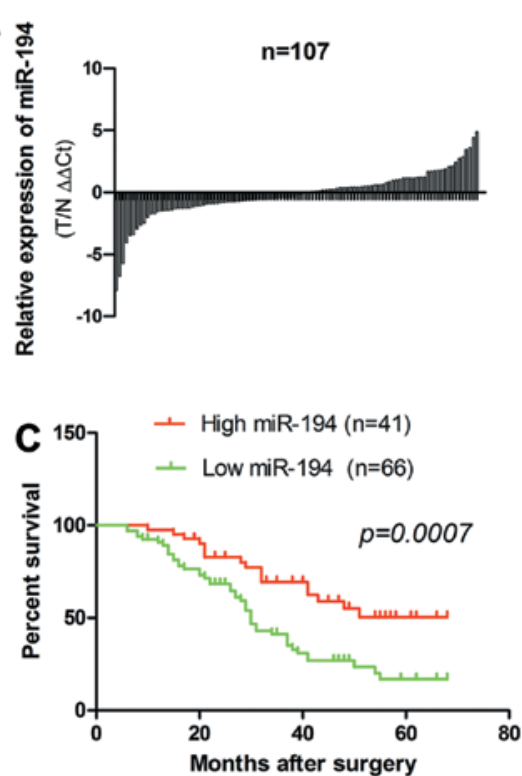
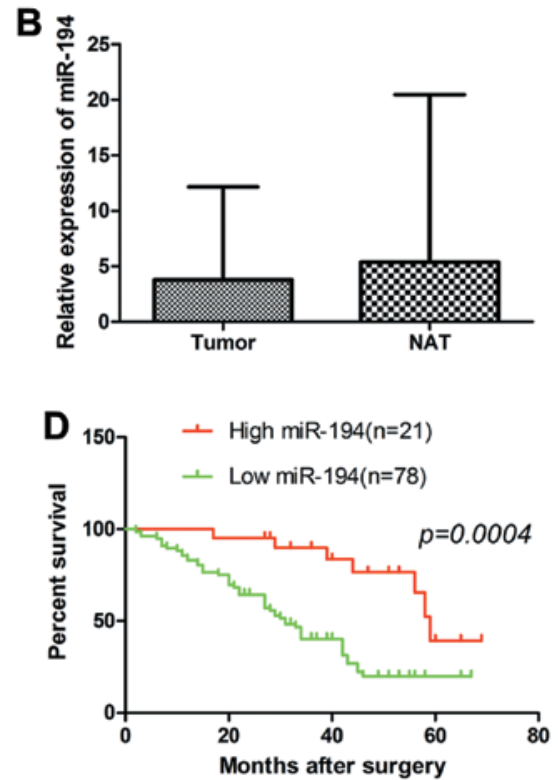

Figure 7. Expression level of miR-194 in 107 osteosarcoma patients and 99 osteosarcoma formalin- or paraformalin-fixed, paraffin-embedded (FFPE) tissues. (A) Relative levels of miR-194 in 107 surgical specimens of osteosarcoma and matched adjacent non-cancerous tissues was quantified by qRT-PCR. Data are presented as $\log 2$ fold change $\left(\Delta \Delta \mathrm{C}_{\mathrm{T}}\right.$ values, tumor/non-cancerous tissues, $\left.\mathrm{T} / \mathrm{N}\right)$. (B) Means of miR-194 relative levels for 107 surgical specimens of osteosarcoma and the matched adjacent non-cancerous tissues. Data are presented as $2^{-\Delta \Delta \mathrm{Ct}}$ values $(\mathrm{P}=0.291)$. (C) Decreased expression of miR-194 was correlated with poor survival in osteosarcoma patients. Log-rank tests show that patients with high miR-194 expression survived significantly longer ( $\mathrm{P}=0.0007)$ than those with low miR-194 expression. The median miR-194 expression level (3.647) in the tumor samples was chosen as the cut-off point. (D) Decreased expression of miR-194 was correlated with poor survival in osteosarcoma FFPE patients. Log-rank tests show that patients with high miR-194 expression survived significantly longer $(\mathrm{P}=0.0004)$ than those with low miR-194 expression. The median miR-194 expression level (5.74) in the tumor samples was chosen as the cut-off point. Columns, mean of three independent experiments; bars, SD.

Expression of miR-194 in osteosarcoma and corresponding non-cancerous tissues. miR-194 expression was decreased in 59 of $107(55.14 \%)$ tumor samples compared with their non-malignant counterparts by real-time PCR (Fig. 7A). U6 was used as a control. However, no statistically significant difference was observed between the cancer tissues (mean \pm SD, 3.6467 \pm 7.44944 ) and matched non-tumor adjacent tissues (NATs) (mean \pm SD, 5.3679 \pm 15.09357$)$ $(\mathrm{P}=0.291)$ (Fig. 7B).

Downregulation of miR-194 is associated with advanced clinicopathological features of osteosarcoma. The median miR-194 expression level in 107 patients with osteosarcoma was 3.647. Patients were divided into two groups according to their expression levels of miR-194, using its median as a cut-off: high miR-194 expression group $(n=41)$ and low miR-194 expression group $(n=66)$. As shown in Table I, we found statistically significant relationships between miR-194 expression and age $(\mathrm{P}=0.0015)$, clinical stage $(\mathrm{P}=0.019)$, distant metastasis $(\mathrm{P}=0.0251)$ and patient mortality $(\mathrm{P}=0.0065)$. No significant difference was observed between the expression of miR-194 and the patient gender $(\mathrm{p}=0.4038)$ and tumor size $(\mathrm{P}=0.6264)$.

The median of miR-194 expression levels in all 99 paraformalin-fixed, paraffin-embedded (FFPE) tissues with osteosarcoma was 5.74. The FFPE tissues were also divided: high miR-194 expression group $(n=21)$ and low miR-194 expression group $(n=78)$. As shown in Table II, we found statistically significant relationships between miR-194 expression and age $(\mathrm{P}=0.037)$, tumor size $(\mathrm{P}=0.041)$, clinical stage $(\mathrm{P}=0.039)$, distant metastasis $(\mathrm{P}=0.044)$ and patient mortality
$(\mathrm{P}=0.013)$. No significant difference was observed between the expression of miR-194 and the patient gender $(\mathrm{P}=0.749)$. These results revealed that loss of miR-194 was associated with some clinicopathological features of OS.

Downregulation of miR-194 confers poor prognosis in patients with osteosarcoma. Patients with high miR-194 expression survived significantly longer compared with low miR-194 expression based on the log rank test (Fig. 7C; p=0.0007). Similar results were obtained with FFPE tissues (Fig. 7D; $\mathrm{P}=0.0004)$. These results revealed that downregulation of miR-194 was associated with poor prognosis of OS.

To identify whether miR-194 was an independent prognostic covariate for osteosarcoma, we performed a multivariate Cox proportional hazards analysis. In the final multivariate Cox regression model, low levels of miR-194 expression in osteosarcoma $(\mathrm{P}=0.001$, relative risk $=0.390)$ and distant metastasis $(\mathrm{P}=0.001$, relative risk $=2.386)$ were associated with a poor prognosis in terms of overall survival, independent of other clinical covariates (Table III). Similar results were obtained in FFPE tissues (Table III; $\mathrm{P}=0.023$, relative risk $=0.371$ ).

CDH2 and IGF1R are potential targets of $m i R-194$. We examined the potential targets of miR-194 by searching the PicTar miRanda and TargetScan databases. We identified a conserved domain within the 3'-UTR of $\mathrm{CDH} 2(\mathrm{~N}$-cadherin) and IGF1R with a potential miR-194 binding site (Fig. 8A). We examined the expression of $C D H 2$ and IGFIR on mRNA and protein levels in OE, blank, control and KD SOSP-9607 cells using real-time PCR and western blot analysis. The results showed that miR-194 had no effect on $C D H 2$ and $I G F 1 R$ mRNA levels 
Table I. Relationship between expression of miR-194, N-cadherin and IGF1R and clinicopathological factors in 107 osteosarcoma patients.

\begin{tabular}{|c|c|c|c|c|c|c|c|c|c|c|}
\hline \multirow[b]{2}{*}{ Characteristics } & \multirow[b]{2}{*}{ No. } & \multicolumn{2}{|c|}{ miR-194 expression } & \multirow[b]{2}{*}{ P-value } & \multicolumn{2}{|c|}{ N-cadherin expression } & \multirow[b]{2}{*}{ P-value } & \multicolumn{2}{|c|}{ IGF1R expression } & \multirow[b]{2}{*}{ P-value } \\
\hline & & Low no. & High no. & & Low no. & High no. & & Low no. & High no. & \\
\hline Gender & & & & 0.130 & & & 0.8110 & & & 0.4753 \\
\hline Male & 62 & 42 & 20 & & 29 & 33 & & 26 & 36 & \\
\hline Female & 45 & 24 & 21 & & 20 & 25 & & 22 & 23 & \\
\hline Age (years) & & & & $0.0052^{\mathrm{a}}$ & & & 0.0957 & & & 0.5904 \\
\hline$\geq 18$ & 35 & 15 & 20 & & 12 & 23 & & 17 & 18 & \\
\hline$<18$ & 72 & 51 & 21 & & 37 & 35 & & 31 & 41 & \\
\hline Tumor size $\left(\mathrm{cm}^{2}\right)$ & & & & 0.1098 & & & 0.0769 & & & $0.0172^{\mathrm{a}}$ \\
\hline$\geq 50$ & 47 & 25 & 22 & & 17 & 30 & & 15 & 32 & \\
\hline$<50$ & 60 & 41 & 19 & & 32 & 28 & & 33 & 27 & \\
\hline Clinical stage & & & & $0.0034^{\mathrm{a}}$ & & & $0.0234^{\mathrm{a}}$ & & & 0.1218 \\
\hline IIA & 32 & 13 & 19 & & 20 & 12 & & 18 & 14 & \\
\hline IIB/III & 75 & 53 & 22 & & 29 & 46 & & 30 & 45 & \\
\hline Distant metastasis & & & & $0.0058^{\mathrm{a}}$ & & & $0.0081^{\mathrm{a}}$ & & & $0.0139^{\mathrm{a}}$ \\
\hline Yes & 52 & 39 & 13 & & 17 & 35 & & 17 & 35 & \\
\hline No & 55 & 27 & 28 & & 32 & 23 & & 31 & 24 & \\
\hline Status & & & & $0.0065^{\mathrm{a}}$ & & & $0.0037^{\mathrm{a}}$ & & & $0.0221^{\mathrm{a}}$ \\
\hline Survival & 45 & 21 & 24 & & 28 & 17 & & 26 & 19 & \\
\hline Death & 62 & 45 & 17 & & 21 & 41 & & 22 & 40 & \\
\hline
\end{tabular}

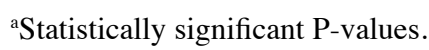

Table II. Relationship between expression of miR-194 and clinicopathological factors in 99 osteosarcoma formalin- or paraformalin-fixed, paraffin-embedded (FFPE) tissues.

\begin{tabular}{lccc}
\hline & \multicolumn{3}{c}{ miR-194 expression } \\
\cline { 2 - 4 } Characteristics & No. of cases & Mean \pm SD & P-value \\
\hline Gender & & & 0.749 \\
Male & 55 & $5.9304 \pm 13.23676$ & \\
Female & 44 & $4.6715 \pm 6.96565$ & \\
Age (years) & & & $0.037^{\mathrm{a}}$ \\
$\geq 18$ & 41 & $11.5227 \pm 15.43802$ & \\
$<18$ & 54 & $1.4141 \pm 2.63859$ & \\
Tumor size $\left(\mathrm{cm}^{2}\right)$ & & & $0.041^{\mathrm{a}}$ \\
$\geq 50$ & 36 & $1.3000 \pm 3.38195$ & \\
$<50$ & 63 & $7.7371 \pm 12.95206$ & \\
Clinical stage & & & $0.039^{\mathrm{a}}$ \\
IIA & 27 & $12.9419 \pm 15.69269$ & \\
IIB/III & 72 & $1.6235 \pm 4.33862$ & \\
Distant metastasis & & & $0.044^{\mathrm{a}}$ \\
Yes & 48 & $1.6254 \pm 4.66794$ & \\
No & 51 & $10.5140 \pm 14.59265$ & \\
Status & & & $0.013^{\mathrm{a}}$ \\
Survival & 47 & $9.4371 \pm 13.60451$ & \\
Death & 52 & $0.5538 \pm 0.58681$ & \\
\hline & & & \\
\hline
\end{tabular}

aStatistically significant P-values.
(Fig. 8C and D). However, the level of endogenous $N$-cadherin protein in OE SOSP-9607 cells was reduced compared with the other three cells normalized to an endogenous reference $\beta$-actin protein (Fig. 8B). Overexpression of $N$-cadherin protein was also found in KD SOSP-9607 cells compared with the other three groups of cells (Fig. 8B). Western blot analysis demonstrated a significant decrease in endogenous $I G F 1 R$ levels in OE group compared with the other three groups (Fig. 8B). The results indicate that miR-194 may target $\mathrm{CDH} 2$ and $I G F 1 R$.

We assessed the interaction of miR-194 with luciferase reporter assay in SOSP-9607 cells using a pMIR-REPORT ${ }^{\mathrm{TM}}$ Luciferase vector containing the 3 '-UTR of $C D H 2$ or a control pMIR-REPORT ${ }^{\mathrm{TM}}$ Luciferase vector containing the same 3'-UTR with mutated miR-194 seed nucleotides. Renilla luciferase vector was used for normalization. The miR-194-up cells significantly repressed the luciferase activity of the vector with the wild-type $\mathrm{CDH} 2$ 3'-UTR, whereas mutation of the seed sequence abolished this repression (Fig. 8E and F). Similar results of the IGFIR were also obtained (Fig. 8G and H).

Expression of IGFIR and N-cadherin proteins were both inversely correlated with miR-194 expression and regulated the migration and invasion of osteosarcoma cells. We examined IGFIR and $N$-cadherin protein expression in 107 patients with osteosarcoma using real-time quantitative PCR. Of the 41 osteosarcoma cases with elevated miR-194, 25 (61.0\%) showed low levels of $N$-cadherin. High levels of $N$-cadherin were present in 42 of $66(63.6 \%)$ cases with downregulated 
Table III. Multivariate Cox regression analysis of prognostic variables in osteosarcoma and osteosarcoma FFPE tissues.

\begin{tabular}{lcccrrr}
\hline & Variables & B & P-value & Wald & Relative risk & 95\% Confidence interval \\
\hline \multirow{2}{*}{107 osteosarcoma tissues } & miR-194 expression & -0.943 & $0.001^{\mathrm{a}}$ & 11.813 & 0.390 & $0.228-0.667$ \\
& Age & -0.020 & 0.937 & 0.006 & 0.980 & $0.595-1.614$ \\
& Clinical stage & -0.261 & 0.297 & 0.771 & 0.771 & $0.431-1.378$ \\
& Distant metastasis & 0.870 & $0.001^{\mathrm{a}}$ & 10.493 & 2.386 & $1.410-4.038$ \\
& Tumor size $\left(\mathrm{cm}^{2}\right)$ & 0.470 & 0.091 & 2.851 & 1.599 & $0.927-2.759$ \\
& miR-194 expression & -0.991 & $0.023^{\mathrm{a}}$ & 5.193 & 0.371 & $0.158-0.871$ \\
& Age & 0.036 & 0.893 & 0.018 & 1.037 & $0.612-1.756$ \\
& Clinical stage & -0.300 & 0.321 & 0.985 & 0.741 & $0.409-1.340$ \\
& Distant metastasis & 0.898 & $0.005^{\mathrm{a}}$ & 7.913 & 2.455 & $1.313-4.592$ \\
& Tumor size $\left(\mathrm{cm}^{2}\right)$ & 0.308 & 0.260 & 1.269 & 1.360 & $0.796-2.324$ \\
\hline
\end{tabular}

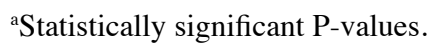

A
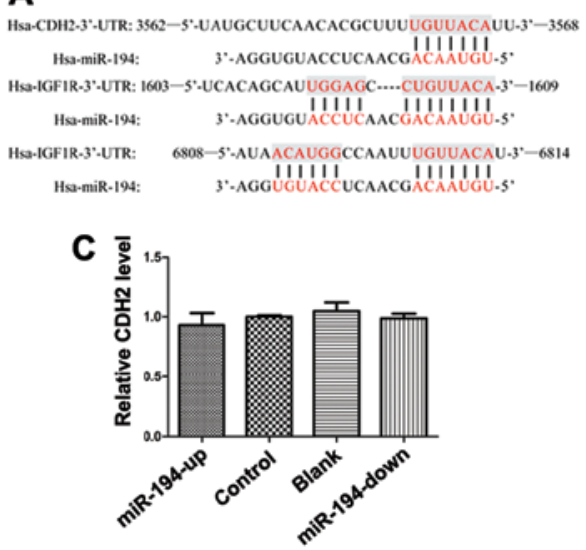

E

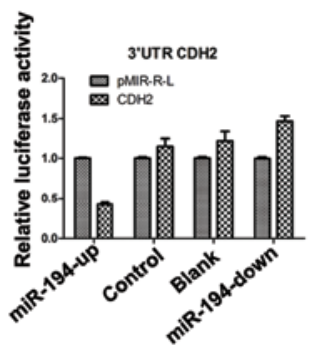

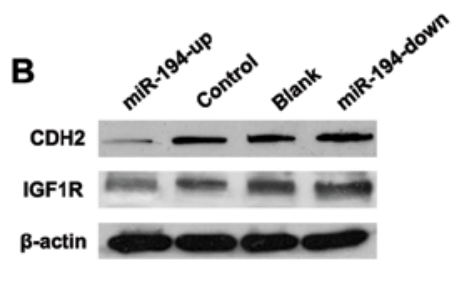
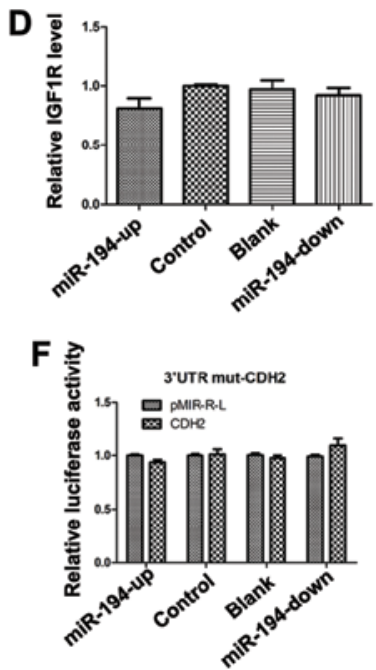
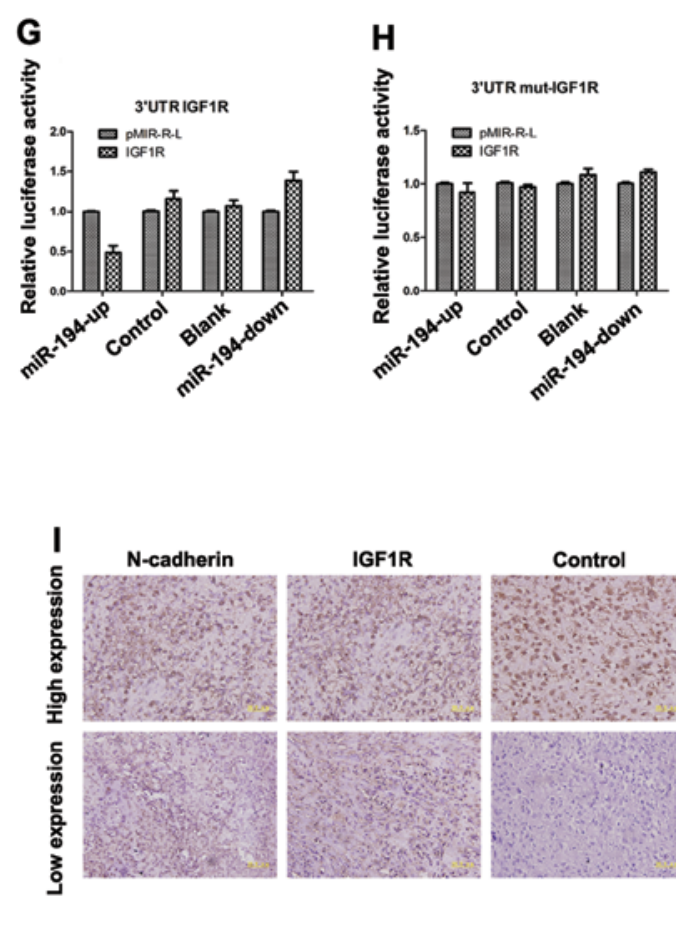
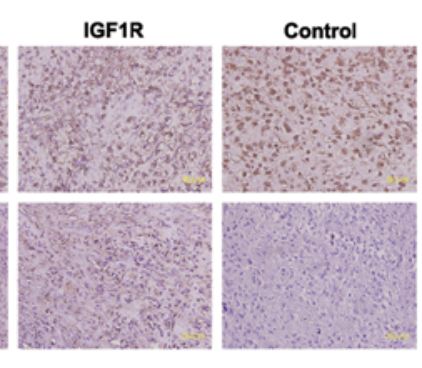

Figure 8. miR-194 target CDH2 and IGF1R in osteosarcoma. (A) Sites of complementarity sequences between microRNAs and CDH2or IGF1R mRNA. (B) Western blotting showed that miR-194 interacted with CDH2 or IGF1R and negatively regulated its expression at the translational level. (C and D) Realtime PCR revealed that miR-194 had no effect on CDH2 or IGF1R in mRNA level. (E and F) Luciferase assays indicated that miR-194 downregulated the expression of $\mathrm{CDH} 2$. Relative repression of the firefly Luciferase expression was standardized for transfection control, Renilla luciferase. PMIR-REPORT ${ }^{\mathrm{TM}}$ luciferase (pMIR-R-L; Promega) was used as empty vector. (G and H) Luciferase assays indicated that miR-194 downregulated the expression of IGF1R. Relative repression of the firefly Luciferase expression was standardized for transfection control, Renilla luciferase. PMIR-REPORT ${ }^{\mathrm{TM}}$ luciferase (pMIR-R-L; Promega) was used as empty vector. (I) Inverse correlation of expression of miR-194 and N-cadherin and IGF1R in human osteosarcoma. Expressions of $\mathrm{N}$-cadherin and IGF1R were analyzed in 99 paraffin specimens of osteosarcoma tissues with immunohistochemical staining and classified as follows: $0-4$, low; 5-9, high. All experiments were repeated three times in triplicate. Columns, mean of three independent experiments; bars, $\mathrm{SD} ;{ }^{*} \mathrm{P}<0.05,{ }^{* *} \mathrm{P}<0.01,{ }^{* * * *} \mathrm{P}<0.001$.

miR-194 $(\mathrm{P}<0.05)$. Of the 41 osteosarcoma cases with elevated miR-194, 29 (70.7\%) had low levels of IGF1R. High levels of $I G F 1 R$ were seen in 47 of $66(71.2 \%)$ cases with downregulated miR-194 $(\mathrm{P}<0.001)$ (Table IV). These findings suggest that expression of the IGFIR and $N$-cadherin proteins were inversely correlated with miR-194 expression in osteosarcoma.
We then examined $I G F I R$ and $N$-cadherin protein expression in 99 paraffin specimens of osteosarcoma using immunohistochemistry analysis. Representative images of $I G F I R$ and $N$-cadherin are shown (Fig. 8I) and analyzed (Table IV). Of the 21 osteosarcoma cases with elevated miR-194, 16 (76.2\%) showed low levels of $N$-cadherin. High 
Table IV. Inverse correlation of expression of miR-194 and N-cadherin and IGF1R in osteosarcoma (using real-time quantitative PCR) and osteosarcoma FFPE tissues (using immunohistochemistry analysis).

\begin{tabular}{|c|c|c|c|c|}
\hline & Group & High miR-194, n (\%) & Low miR-194, n (\%) & In all \\
\hline \multirow[t]{6}{*}{107 osteosarcoma tissues } & High N-cadherin & $16(39.0)$ & $42(63.6)$ & 58 \\
\hline & Low N-cadherin & $25(61.0)$ & $24(36.4)$ & 49 \\
\hline & In all & 41 & 66 & 107 \\
\hline & High IGF1R & $12(29.3)$ & $47(71.2)$ & 59 \\
\hline & Low IGF1R & $29(70.7)$ & $19(28.8)$ & 48 \\
\hline & In all & 41 & 66 & 107 \\
\hline \multirow[t]{6}{*}{99 FFPE tissues } & High N-cadherin & $5(23.8)$ & $51(65.4)$ & 56 \\
\hline & Low N-cadherin & $16(76.2)$ & $27(34.6)$ & 43 \\
\hline & In all & 21 & 78 & 99 \\
\hline & High IGF1R & $6(28.6)$ & $62(79.5)$ & 68 \\
\hline & Low IGF1R & $15(71.4)$ & $16(20.5)$ & 31 \\
\hline & In all & 21 & 78 & 99 \\
\hline
\end{tabular}

levels of $N$-cadherin were present in 51 of $78(65.4 \%)$ cases with downregulated miR-194 $(\mathrm{P}<0.01)$. Of the 21 osteosarcoma cases with elevated miR-194, 15 (71.4\%) had low levels of IGF1R. High levels of IGF1R were seen in 62 of $78(79.5 \%)$ cases with downregulated miR-194 $(\mathrm{P}<0.001)$. These findings suggest that expression of the IGFIR and $N$-cadherin proteins were inversely correlated with miR-194 expression in osteosarcoma.

The expression of $\mathrm{N}$-cadherin was associated with clinical stage $(\mathrm{P}=0.0354)$, distant metastasis $(\mathrm{P}=0.0271)$ and survival $(\mathrm{P}=0.0014)$, while the expression of $I G F 1 R$ was associated with tumor size $(\mathrm{P}=0.0101)$, distant metastasis $(\mathrm{P}=0.0259)$ and survival $(\mathrm{P}=0.0253)$ (Table I).

\section{Discussion}

Osteosarcoma is the most frequent primary solid malignancy of bone, which is defined by the presence of malignant mesenchymal cells which produce osteoid and/or immature bone (40). Approximately $20 \%$ of patients present with lung metastases at initial diagnosis and in $40 \%$ of patients metastases occur at a later stage. Eighty percent of all metastases arise in the lungs, most commonly in the periphery of the lungs, and exhibit resistance to conventional chemotherapy (41).

Uncontrolled cell proliferation and aggressive tumor cell metastasis are two essential steps during cancer progression. Therefore, in the present study, we investigated the effects of miR-194 on tumor growth and metastasis of osteosarcoma. We showed that overexpressed miR-194 significantly suppressed proliferation, migration and invasion of SOSP9607 and U2-OS cells in vitro. Our mouse model showed that miR-194 also significantly inhibited orthotopic tumor growth and lung metastasis in vivo. We have performed the largest study to date that assessed the expression levels of miR-194 in osteosarcoma by real-time PCR. However, no significant difference of miR-194 expression was found in 107 cancerous and adjacent non-cancerous tissue pairs. Tissue specificity might be one of the reasons which was associated with the differences in miR-194 expression, as observed in cancer miRNA signatures across different organs (42). Furthermore, different osteosarcoma cell lines show different expression profiles of invasion, motility and colony formation, with different mRNAs and miRNA expression (43). We observed that decreased expression of miR-194 was correlated with cancer progression and poor prognosis in osteosarcoma patients, independent of other clinicopathologic factors. Therefore, upregulated miR-194 was very effective in inhibiting tumor growth and metastasis indicating that miR-194 functions as a tumor suppressor gene and as a potential therapeutic target.

Generally, metastatic models are conducted in nude mice by injecting human osteosarcoma cells either intravenously or subcutaneously (32). However, these models are not clinically relevant since osteosarcoma does not occur spontaneously (44). In the present study, we selected a spontaneous metastatic model involving orthotopic transplantation of osteosarcoma cells resulting in spontaneous pulmonary metastases (32). The microenvironment of tibia in nude mice resembled the tumor progression and metastases development clinically.

Cadherins have a role in $\mathrm{Ca}^{2+}$-dependent cell-cell interaction (45) as well as acting as metastasis promoting or suppressing proteins in different cancers $(46,47)$. Insulin and insulin-like growth factor receptor (IGFR)-mediated molecular pathways are important effectors of neoplastic transformation in nonsmall cell lung cancer (48) and squamous cell carcinoma of the head and neck (49). IGFIR has a major role in cancer cell proliferation and survival, and confers resistance to cytotoxic, hormonal and targeted therapies (50). Our results indicate that miR-194 interacted with $N$-cadherin and IGF-IR and negatively regulated their expression at the translational level, which also indicated that miR-194 may suppress tumor growth and metastasis in osteosarcoma cells by downregulating $N$-cadherin and IGF-IR.

Unlike siRNAs, which silence the expression of a single gene, miRNAs mainly silence the expression of multiple genes simultaneously. It is estimated that an average miRNA may have more than 100 targets (51). It is crucial to identify 
additional target genes that mediate the miR-194-induced regulation of tumor metastasis. Predicting and identifying the miR-194-targeting genes provides an experimental basis for further research on regulatory mechanism of miR-194. By using TargetScan 5.1 and PicTar, we predicted putative genes of miR-194, and obtained several putative targets correlating with tumor growth or metastasis, such as QKI, KIAA1239, EPHA5, NACC2, MCTS1 and SAMD4A. In general, the discovery of miRNA and their functions, has introduced a new dimension to our existing knowledge of signaling molecules and pathways for more precise therapeutic targeting. Further investigation is required for characterization of miR-194 and other miRNAs as prognostic and/or diagnostic markers in human osteosarcoma.

In conclusion, the results demonstrate that miR-194 affected the growth and metastasis of osteosarcoma cells both in vitro and in vivo. Overexpression of miR-194 downregulated the expression of N-cadherin and IGF-IR protein, suggesting that miR-194 functions as tumor suppressor probably by downregulating N-cadherin and IGF-IR in osteosarcoma. Downregulation of miR-194 may be associated with tumor aggressiveness and tumor metastasis of osteosarcoma, suggesting that miR-194 may be an independent prognostic marker for osteosarcoma. Other putative miR-194 target genes that are potentially associated with the growth and metastasis of osteosarcoma cells should be investigated. Finally, miR-194 may prove to be a promising gene therapeutic agent. It could be informative to confirm the putative target genes and further investigate the underlying molecular mechanisms of miR-194 as a tumor suppressor gene in osteosarcoma.

\section{Acknowledgements}

We would like to thank Chengkui Cai, Qiong Ma, GuangyiZhao, Yanhua Wen, Yunyan Liu, Lei Jin, Yinglong Zhang, Shiju Yan, Cong Sun, Xin Wang and Chuan Dong for their excellent technical assistance and helpful discussions.

\section{References}

1. Mirabello L, Troisi RJ and Savage SA: Osteosarcoma incidence and survival rates from 1973 to 2004: data from the Surveillance, Epidemiology, and End Results Program. Cancer 115: 1531-1543, 2009.

2. Marina N, Gebhardt M, Teot L and Gorlick R: Biology and therapeutic advances for pediatric osteosarcoma. Oncologist 9 : 422-441, 2004.

3. Picci P: Osteosarcoma (osteogenic sarcoma). Orphanet J Rare Dis 2: 6, 2007.

4. Ambros V: microRNAs: tiny regulators with great potential. Cell 107: 823-826, 2001

5. Bartel DP: MicroRNAs: genomics, biogenesis, mechanism, and function. Cell 116: 281-297, 2004.

6. Lee RC, Feinbaum RL and Ambros V: The C. elegans heterochronic gene lin-4 encodes small RNAs with antisense complementarity to lin-14. Cell 75: 843-854, 1993.

7. Sarver AL, Li L and Subramanian S: MicroRNA miR-183 functions as an oncogene by targeting the transcription factor EGR1 and promoting tumor cell migration. Cancer Res 70: 9570-9580, 2010.

8. Gong C, Yao Y, Wang Y, et al: Up-regulation of miR-21 mediates resistance to trastuzumab therapy for breast cancer. J Biol Chem 286: 19127-19137, 2011.

9. Mei J, Bachoo R and Zhang CL: MicroRNA-146a inhibits glioma development by targeting Notch1. Mol Cell Biol 31: 3584-3592, 2011.
10. Suh SS, Yoo JY, Nuovo GJ, et al: MicroRNAs/TP53 feedback circuitry in glioblastoma multiforme. Proc Natl Acad Sci USA 109: 5316-5321, 2012.

11. Qi P, Cheng SQ, Wang H, Li N, Chen YF and Gao CF: Serum microRNAs as biomarkers for hepatocellular carcinoma in Chinese patients with chronic hepatitis B virus infection. PLoS One 6: e28486, 2011.

12. Dang X, Ma A, Yang L, et al: MicroRNA-26a regulates tumorigenic properties of EZH2 in human lung carcinoma cells. Cancer Genet 205: 113-123, 2012

13. Suzuki H, Yamamoto E, Nojima M, et al: Methylation-associated silencing of microRNA-34b/c in gastric cancer and its involvement in an epigenetic field defect. Carcinogenesis 31: 2066-2073, 2010.

14. Lu J, Getz G, Miska EA, et al: MicroRNA expression profiles classify human cancers. Nature 435: 834-838, 2005.

15. Saito Y,Liang G, Egger G, et al: Specific activation of microRNA127 with downregulation of the proto-oncogene BCL6 by chromatin-modifying drugs in human cancer cells. Cancer Cell 9: 435-443, 2006.

16. Yan K, Gao J, Yang T, et al: MicroRNA-34a inhibits the proliferation and metastasis of osteosarcoma cells both in vitro and in vivo. PLoS One 7: e33778, 2012.

17. Wu Q, Jin $\mathrm{H}$, Yang Z, et al: MiR-150 promotes gastric cancer proliferation by negatively regulating the pro-apoptotic gene EGR2. Biochem Biophys Res Commun 392: 340-345, 2010.

18. Chow TF, Mankaruos M, Scorilas A, et al: The miR-17-92 cluster is over expressed in and has an oncogenic effect on renal cell carcinoma. J Urol 183: 743-751, 2010.

19. Deng S, Calin GA, Croce CM, Coukos G and Zhang L: Mechanisms of microRNA deregulation in human cancer. Cell Cycle 7: 2643-2646, 2008.

20. Zhang B, Pan X, Cobb GP and Anderson TA: microRNAs as oncogenes and tumor suppressors. Dev Biol 302: 1-12, 2007.

21. Slaby O, Svoboda M, Fabian P, et al: Altered expression of miR-21, miR-31, miR-143 and miR-145 is related to clinicopathologic features of colorectal cancer. Oncology 72: 397-402, 2007.

22. Kloosterman WP and Plasterk RH: The diverse functions of microRNAs in animal development and disease. Dev Cell 11: 441-450, 2006.

23. Hino K, Tsuchiya K, Fukao T, et al: Inducible expression of microRNA-194 is regulated by HNF-1 $\alpha$ during intestinal epithelial cell differentiation. RNA 14: 1433-1442, 2008.

24. Meng Z, Fu X, Chen X, et al: miR-194 is a marker of hepatic epithelial cells and suppresses metastasis of liver cancer cells in mice. Hepatology 52: 2148-2157, 2010.

25. Krutzfeldt J, Rosch N, Hausser J, Manoharan M, Zavolan M and Stoffel M: MicroRNA-194 is a target of transcription factor 1 (Tcf1, HNF1 $\alpha$ ) in adult liver and controls expression of frizzled- 6 . Hepatology 55: 98-107, 2012.

26. Le XF, Almeida MI, Mao W, et al: Modulation of MicroRNA194 and cell migration by HER2-targeting trastuzumab in breast cancer. PLoS One 7: e41170, 2012.

27. Hino K, Fukao T and Watanabe M: Regulatory interaction of HNF1- $\alpha$ to microRNA-194 gene during intestinal epithelial cell differentiation. Nucleic Acids Symp Ser (Oxf) 51: 415-416, 2007.

28. Braun CJ, Zhang X, Savelyeva I, et al: p53-Responsive micrornas 192 and 215 are capable of inducing cell cycle arrest. Cancer Res 68: 10094-10104, 2008.

29. Song Y, Zhao F, Wang Z, et al: Inverse association between miR-194 expression and tumor invasion in gastric cancer. Ann Surg Oncol 19 (Suppl 3): S509-S517, 2012.

30. Dong P, Kaneuchi M, Watari H, et al: MicroRNA-194 inhibits epithelial to mesenchymal transition of endometrial cancer cells by targeting oncogene BMI-1. Mol Cancer 10: 99, 2011.

31. Pichiorri F, Suh SS, Rocci A, et al: Downregulation of p53-inducible microRNAs 192, 194, and 215 impairs the p53/ MDM2 autoregulatory loop in multiple myeloma development. Cancer Cell 18: 367-381, 2010.

32. Chen X, Yang TT, Wang W, et al: Establishment and characterization of human osteosarcoma cell lines with different pulmonary metastatic potentials. Cytotechnology 61: 37-44, 2009.

33. Zhao G, Cai C, Yang T, et al: MicroRNA-221 induces cell survival and cisplatin resistance through PI3K/Akt pathway in human osteosarcoma. PLoS One 8: e53906, 2013.

34. Sun D, Yang K, Zheng G, Li Z and Cao Y: Study on effect of peptide-conjugated near-infrared fluorescent quantum dots on the clone formation, proliferation, apoptosis, and tumorigenicity ability of human buccal squamous cell carcinoma cell line BcaCD885. Int J Nanomed 5: 401-405, 2010. 
35. Naito S, von Eschenbach AC, Giavazzi R and Fidler IJ: Growth and metastasis of tumor cells isolated from a human renal cell carcinoma implanted into different organs of nude mice. Cancer Res 46: 4109-4115, 1986.

36. Pan Z, Zhao W, Zhang X, et al: Scutellarin alleviates interstitial fibrosis and cardiac dysfunction of infarct rats by inhibiting TGF $\beta 1$ expression and activation of p38-MAPK and ERK1/2. Br J Pharmacol 162: 688-700, 2011

37. Osaki M, Takeshita F, Sugimoto Y, et al: MicroRNA-143 regulates human osteosarcoma metastasis by regulating matrix metalloprotease-13 expression. Mol Ther 19: 1123-1130, 2011.

38. Kong W, He L, Coppola M, et al: MicroRNA-155 regulates cell survival, growth, and chemosensitivity by targeting FOXO3a in breast cancer. J Biol Chem 285: 17869-17879, 2010.

39. Grenman R, Burk D, Virolainen E, et al: Clonogenic cell assay for anchorage-dependent squamous carcinoma cell lines using limiting dilution. Int J Cancer 44: 131-136, 1989.

40. Arndt CA, Rose PS, Folpe AL and Laack NN: Common musculoskeletal tumors of childhood and adolescence. Mayo Clin Proc 87: 475-487, 2012

41. Bacci G, Rocca M, Salone M, et al: High grade osteosarcoma of the extremities with lung metastases at presentation: treatment with neoadjuvant chemotherapy and simultaneous resection of primary and metastatic lesions. J Surg Oncol 98: 415-420, 2008.

42. Baffa R, Fassan M, Volinia S, et al: MicroRNA expression profiling of human metastatic cancers identifies cancer gene targets. J Pathol 219: 214-221, 2009.

43. Lauvrak SU, Munthe E, Kresse SH, et al: Functional characterisation of osteosarcoma cell lines and identification of mRNAs and miRNAs associated with aggressive cancer phenotypes. Br J Cancer 109: 2228-2236, 2013.
44. Miretti S, Roato I, Taulli R, et al: A mouse model of pulmonary metastasis from spontaneous osteosarcoma monitored in vivo by Luciferase imaging. PLoS One 3: e1828, 2008.

45. Angst BD, Marcozzi C and Magee AI: The cadherin superfamily: diversity in form and function. J Cell Sci 114: 629-641, 2001.

46. Stemmler MP: Cadherins in development and cancer. Mol Biosyst 4: 835-850, 2008.

47. Derycke LD and Bracke ME: N-cadherin in the spotlight of cell-cell adhesion, differentiation, embryogenesis, invasion and signalling. Int J Dev Biol 48: 463-476, 2004.

48. Dziadziuszko R, Merrick DT, Witta SE, et al: Insulin-like growth factor receptor 1 (IGF1R) gene copy number is associated with survival in operable non-small-cell lung cancer: a comparison between IGF1R fluorescent in situ hybridization, protein expression, and mRNA expression. J Clin Oncol 28: 2174-2180, 2010

49. Meyer F, Samson E, Douville P, Duchesne T, Liu G and Bairati I: Serum prognostic markers in head and neck cancer. Clin Cancer Res 16: 1008-1015, 2010.

50. Munagala R, Aqil F and Gupta RC: Promising molecular targeted therapies in breast cancer. Indian J Pharmacol 43: 236-245, 2011.

51. Griffiths-Jones S, Saini HK, van Dongen S and Enright AJ: miRBase: tools for microRNA genomics. Nucleic Acids Res 36: D154-D158, 2008. 